\title{
Representações Diversificadas Do Corpo Feminino Em League Of Legends
}

Diversified Representations of the Female Body in League of Legends

FARIA, Mônica Lima de; Doutora; Universidade Federal de Pelotas

monicalfaria@gmail.com

NUNES, Victor Henrique; Bacharel; Universidade Federal de Pelotas

vitornunes@live.com

\section{Resumo}

Este estudo analisa as diversas representações do corpo feminino no jogo online League of Legends, a partir de imagens promocionais 2D, apontando as feminilidades diversificadas e problematizando a atualização de discurso do jogo através da criação de personagens femininas com corpos diversificados. A análise busca identificar personagens concebidas de maneira diversificada, como personagens que são andróginas, ou então, personagens que não possuem marcadores identitários femininos e apresentar uma breve discussão sobre a erotização e idealização do corpo feminino nos jogos eletrônicos.

Palavras Chave: jogos digitais, corpos diversificados, League of Legends.

\begin{abstract}
This research analyses the various representations of the female body in the League of Legends online game, from $2 D$ promotional images, pointing out the diverse femininities and problematizing the discourse update of the game through the creation of female characters with diversified bodies. The analysis seeks to identify characters conceived in a diversified way, as characters that are androgynous, characters that do not have feminine identity markers and present a brief discussion about the erotization and idealization of the female body in electronic games.
\end{abstract}

Keywords: digital games, diversified bodies, League of Legends. 


\section{Introdução}

Muito se discute a importância de estudos a respeito de gênero e jogos digitais hoje em dia, assim como a problematização dessas construções, onde muitas vezes, personagens de jogos digitais são idealizadas e erotizadas. O objetivo principal deste artigo é analisar as mais recentes personagens femininas do jogo eletrônico League of Legends, apontando as feminilidades diversificadas e problematizando a atualização do discurso do jogo através da criação de personagens femininas com corpos diversificados.

League of Legends ${ }^{1}$, desenvolvido por Brendon Beck e Marc Merril, é um jogo eletrônico online competitivo baseado em equipes para as plataformas Microsoft Windows e Mac OS X, onde duas equipes de campeões, cada um com design e estilo de jogo único, lutam em campos de batalha em diversos modos de jogo.

O universo de League of Legends é muito rico, sendo situado no mundo fictício conhecido como Runeterra, que abriga diversas regiões. Atualmente o jogo possui 12 regiões e cada uma delas possui suas próprias histórias e características. Além de possuir grande diversidade geográfica, o jogo conta com diversas raças de campeões, como humanos, Yordles, Vastayas (criaturas quiméricas cuja linhagem é composta por sangue humano e pela magia espiritual de uma raça pré-humana), viajantes de galáxias distantes, robôs, crias do Vazio (seres inexplicáveis, terrores que a mente humana é incapaz de entender), seres Ascendentes (seres antropomórficos inteligentes de poderes únicos, que geralmente já foi uma vez humano), Darkins (uma raça antiga alada), Yordles (pequenas criaturas ágeis), entre outros..

O elenco de campeões está sempre em expansão, com atualizações de jogabilidade frequentes. Segundo o especialista Ernest Adams (2010) em seu livro Fundamentals of Game Design, jogos online é um termo usado para se referir a jogos em que as máquinas dos jogadores estão conectadas a uma rede, como por exemplo a internet, assim como entende-se que os jogos baseados em equipes ocorrem quando os membros de uma equipe cooperam e a equipe compete coletivamente contra uma ou mais equipes.

O jogo foi lançado em 2009 pela empresa Riot Games, sendo bem recebido e sua popularidade cresceu ao decorrer dos anos, atingindo a marca de 100 milhões de jogadores mensais em $2016^{2}$. Por ser um jogo grátis e sem restrição de conteúdo que afete a jogabilidade, League of Legends tornou-se muito popular, sendo um dos jogos mais transmitidos online, chegando a 19 milhões de horas assistidas durante uma semana ${ }^{3}$. O jogo recebeu muitas críticas positivas e atualmente possui a pontuação 78 de 100 no site Metacritic ${ }^{4}$.

Rodrigues afirma em seu trabalho que jogos eletrônicos são instrumentos culturais presentes na sociedade:

Os jogos, no decorrer de seus recém completos 50 anos de história, foram capazes de alterar comportamentos das comunidades onde foram inseridos, definindo manias, criando expressões e linguajares próprios e compondo assim seu lugar distinto na

\footnotetext{
${ }^{1}$ Informações disponíveis em <https://br.leagueoflegends.com/pt/>. Acesso em 18 de fevereiro de 2018.

2 Informações disponíveis em < https://www.forbes.com/sites/insertcoin/2016/09/13/riot-games-reveals-league-oflegends-has-100-million-monthly-players/\#16255f0a5aa8>. Acesso em 4 de dezembro 2017.

${ }^{3}$ Informações disponíveis em < https://www.geek.com/games/the-10-most-streamed-video-games-this-week1646668/>. Acesso em 4 de dezembro 2017.

${ }^{4}$ Informações disponíveis em <http://www.metacritic.com/game/pc/league-of-legends>. Acesso em 4 de dezembro 2017.
} 
cibercultura (GULARTE, apud RODRIGUES, 2014, p. 19).

Esses jogos ganham cada vez mais espaço no Brasil, tendo investimento da Agência Nacional do Cinema (Ancine) através do Fundo Setorial do Audiovisual, que disponibilizou o valor de R\$ 10 milhões para a produção de jogos eletrônicos em $2017^{5}$. Os jogos digitais unem diversos campos como cinema, fotografia, ilustração, música e outras tecnologias, tornando-se uma mídia singular que muito tem a ser explorada.

Este artigo busca analisar as personagens femininas de League of Legends, sendo importante entender o público feminino de jogos digitais. Dados revelam que em 2013 o público feminino de jogos digitais ocupavam $41 \%$ do total de jogadores. As mulheres consumidoras de jogos eletrônicos têm crescimento contínuo, sendo elas 53,6\% do total de jogadores de algum jogo eletrônico em $2017^{6}$. Apesar das mulheres serem mais da metade dos jogadores, elas quase não estão envolvidas na indústria de jogos, revelando um grande viés de gênero. Segundo o $1^{\circ}$ Censo da Indústria de Jogos Digitais realizado em 2014, apenas 15\% dos trabalhadores envolvidos com games são do gênero feminino no Brasil. Esses dados acompanham o cenário mundial, onde o número de mulheres na indústria de jogos é baixo. No Reino Unido, apenas $6 \%$ dos trabalhadores são mulheres ${ }^{7}$.

O jogo escolhido possui uma grande variedade de personagens femininas jogáveis, atualmente $48^{8}$, muitas delas concebidas com o corpo magro, esbelto e curvilíneo, seguindo o padrão femme fatale ${ }^{9}$. Como explica Arthur Bobany em seu livro Videogame Arte (2008), a mulher é constantemente fetichizada em videogames e em outras formas de mídia da cultura pop, pois essa idealização é um apelo comercial para o consumidor masculino adolescente e de acordo com dados da "Pesquisa Game Brasil 2017", 28,4\% dos jogadores brasileiros do sexo masculino possuem entre 16 a 24 anos, sendo estes jogadores os consumidores de jogos digitais como League of Legends.

Este artigo determina as feminilidades em League of Legends, identificado seus principais marcadores identitários visuais e fazendo uma reflexão sobre os marcadores visuais que não são normatizados no jogo, contribuindo para a amplificação do trabalho de diplomação Um estudo em representação gráficas nos jogos eletrônicos na perspectiva das relações de gênero: os tipos de feminilidades em League of Legends (2014) da autora Letícia Rodrigues. Entretanto, o artigo tem como foco discutir quais personagens são consideradas fora do padrão magro e curvilíneo, ou seja, diversificadas. Conforme caracteriza Rodrigues (2014) “o termo marcador será aqui utilizado para referir-se a elementos de design e arte visual utilizados para dar significados às personagens em relação às suas características físicas, psicológicas e culturais". A feminilidade é um ponto muito importante nesse artigo, sendo explicada na visão de Beraldo em seu artigo $O$ que é feminilidade? Papéis sociais e o feminismo contemporâneo:

A feminilidade é um conceito cultural bastante naturalizado, porém ainda muito controverso nos estudos feministas. Definida de maneira arbitrária e hegemônica dentro de uma sociedade patriarcal, esta normatividade sobre o que é ser/parecer mulher tem

\footnotetext{
${ }^{5}$ Informações disponíveis em < https://www.ancine.gov.br/pt-br/sala-imprensa/noticias/programa-brasil-de-todastelas-vai-investir-r-10-milh-es-no-desenvolvimento-0>. Acesso em 4 de dezembro 2017.

${ }^{6}$ Informações disponíveis em < https://www.pesquisagamebrasil.com.br>. Acesso em 4 de dezembro de 2017.

${ }^{7}$ Informações disponíveis em < http://www.abragames.org/uploads/5/6/8/0/56805537/i_censo_da_industria_brasileira_de_jogos_digitais.pdf>. Acesso em 4 de dezembro de 2017.

${ }^{8}$ Dados coletados até 5 de dezembro de 2017

${ }^{9}$ Mulher fatal, ou femme fatale é um arquétipo de personagem feminino, geralmente sedutora.
} 
sido bastante questionada desde as primeiras ondas feministas. Afinal o que é ser feminina: um aspecto natural das mulheres ou uma construção de um imaginário cultural e midiático? (BERALDO, 2014, p. 1).

Diferentemente de muitas personagens de League of Legends, as mulheres não possuem os corpos todos iguais. É importante criar uma reflexão sobre representações diversificadas do corpo feminino e discutir sobre a idealização da mulher nos jogos eletrônicos. Ao explorar essas questões, busca-se um olhar crítico em relação a idealização do corpo feminino e as escolhas empregadas no design de personagens de League of Legends. Entende-se por corpos diversificados, personagens que são concebidas não erotizadas ou com corpos fora do padrão magro e curvilíneo, sendo estes corpos o foco do artigo.

\section{Metodologia}

Este artigo utiliza metodologia realizada por Letícia Rodrigues (2014), onde se verifica a presença de marcadores identitários femininos nas ilustrações de promoção do jogo. Rodrigues analisou as personagens lançadas até janeiro de 2014, este artigo propõe-se a atualizar esse cenário, analisando as 48 personagens classificadas como do sexo feminino lançadas até dezembro de 2017.

Foram identificadas e classificadas 48 ilustrações 2D utilizadas para a promoção do jogo, comumente conhecidas como splash art $^{10}$. Os campeões dentro do jogo possuem diversas splash arts, cada campeão teve a sua splash art padrão analisada, também conhecida como splash art clássica. A título de curiosidade, algumas splash arts atualizadas também foram analisadas. A partir das ilustrações verificou-se a presença dos seguintes marcadores identitários femininos: comprimento do cabelo; cabelos esvoaçantes; presença de maquiagem; corpo curvilíneo e magro; roupa decotada; seios em destaque; corpo nu; roupa colada e evidenciando atributos físicos e salto alto. Uma segunda coleta de dados foi realizada utilizando os modelos de personagens em 3D, para verificar a presença do uso de salto alto. Os dados foram coletados e organizados para interpretação e discussão.

\section{Desenvolvimento}

Atualmente League of Legends conta com 139 campeões disponíveis no jogo, sendo apenas 48 personagens femininas. Ou seja, apenas 34,5\% são personagens femininas. Esses dados reforçam as observações de Rodrigues (2014) que afirma que a taxa de campeãs e campeões é desigual, onde uma possível explicação é que consideram o jogador homem como o principal jogador, sendo assim, são criados personagens masculinos para que o jogador masculino se identifique.

Na pesquisa de Rodrigues (2014), um panorama sobre as feminilidades e masculinidades em League of Legends é montado, com dados estatísticos dos 117 personagens lançados até janeiro de 2014. Este artigo visa atualizar a análise de Rodrigues, examinando as novas personagens, além de trazer um panorama focado nas representações femininas diversificadas, aquelas que fogem dos padrões magros e curvilíneos.

\footnotetext{
${ }^{10}$ Splash art é uma ilustração 2D representativa do personagem, utilizada para promover o personagem.
} 
Os resultados são apresentados de forma cronológica para melhor entendimento da linha do tempo de League of Legends e suas criações femininas, entre os anos de 2009 e 2017.

League of Legends estreou em 2009 com um pacote de 40 personagens iniciais, sendo 11 deles do sexo feminino, representando $27,5 \%$ do total de campeões. Dessas 11 personagens femininas, 7 eram mulheres de alguma forma atraente, que utilizavam maquiagens, ou possuíam a pele exposta realçando seus atributos físicos ou seus seios fartos e protuberantes. Apesar do primeiro pacote de campeãs contar com 7 personagens idealizadas e erotizadas, desde os primórdios do jogo podemos notar o esforço para tentar, de alguma maneira, diversificar as representações da feminilidade: o pacote inicial contava com as personagens Anivia, Annie, Kayle e Tristana, que serão analisadas adiante.

Anivia é uma criatura criogênica em forma de fênix ${ }^{11}$ e de, acordo com a análise de Rodrigues (2014), ela não possui nenhum marcador cultural de feminilidade, identificando seu gênero apenas pela sua história de origem e dublagem com voz feminina.

Annie foi a primeira campeã infantil. Ela é uma criança com um grande poder arcano, podendo controlar o fogo. Apesar de ser uma criança, Annie não é uma personagem infantilizada. Ela é sombria e ameaçadora, ainda mais ao lado do seu companheiro enfeitiçado Tibbers, um urso feroz. Segundo Rodrigues (2009), Annie apresenta uma subversão da feminilidade, infância e inocência ao retratar uma "menininha" com poderes "sombrios". Com maquiagem preta nos olhos e em posição de ataque em sua splash art, Rodrigues (2014, p. 146) diz sobre Annie: "deduz-se que ela não seja sexualizada ou objetificada pelas contradições dos valores morais que este processo projetaria sobre a figura de uma criança". Apesar de League of Legends não erotizar personagens infantis, é válido lembrar a presença de Lolicon na cultura japonesa, termo utilizado para se referir a animes ou mangás que ilustram menores de idade em situações eróticas ou de nudez.

Kayle surgiu como uma grande heroína que empunhava uma espada flamejante e protegia seu corpo com uma armadura encantada. A campeã Kayle teve sua splash art atualizada duas vezes durante os seus anos de existência. Em sua primeira splash art, apesar da cintura fina, a personagem não possuía nenhum marcador identitário feminino, já que seu corpo estava completamente coberto por uma armadura, inclusive um elmo que protegia o rosto da campeã e sua posição de ataque não revelava nenhum indício de seios ou a presença de boob plate, termo que de acordo com Rodrigues (2014) é um elemento de armadura que possui a forma de seios, enfatizando seus contornos. Em sua segunda splash art, Kayle continuava portando as mesmas características neutras, não possibilitando a identificação do gênero da personagem, apesar de ser possível notar ao analisar atentamente, a presença de cintura fina e quadril largo. Na terceira versão de sua splash art, Kayle ganhou uma armadura com boob plate.

Tristana é a primeira representante feminina da raça yordle, sendo ela uma campeã atiradora que porta um grande canhão chamado Boomer. De acordo com Rodrigues (2014), a raça yordle representa criaturinhas humanóides que se assemelham a fadas e seres antropomórficos. Tristana possui o corpo padrão de uma yordle, baixo, com cabeça grande, olhos grandes e orelhas grandes e pontudas. $\mathrm{O}$ design dos yordles se assemelha a personagens com estilo chibi. Do ponto de vista de Chris Patmore em seu livro Diseño de Personajes (2006) o estilo de desenho chibi é caracterizado por personagem que possuem olhos muito grandes e se assemelham a crianças. Outras características faciais são pequenas, como nariz e boca. As fêmeas parecem mulheres com

\footnotetext{
${ }^{11}$ Fênix é um pássaro lendário da mitologia grega, que morria e renascia das próprias cinzas.
} 
peles em tons azulados, possuindo orelhas grandes e pontudas, enquanto os homens são mais animalescos, possuindo pelos e focinhos. Os personagens da raça yordle são conhecidos como fofos e carismáticos devido ao pequeno porte e cabeças grandes, as fêmeas dessa raça não são erotizadas no jogo.

Apesar do pacote inicial de campeãs contar com 4 personagens com feminilidades diferenciadas, League of Legends ainda possuía muitas personagens idealizadas e erotizadas sem uma justificativa que tornassem as personagens admissíveis. A personagem Evelynn foi criada como uma campeã assassina, capaz de se fundir às sombras, ela não é totalmente humana e sua herança é um mistério. Evelynn sempre foi uma campeã erotizada com sua roupa de couro, faixas e espinhos, entretanto sua biografia era muito vaga e seu design de personagem não era crível. Marcadores identitários que tornam as personagens atraentes podem ser justificados, conforme afirma Katherine Isbister em seu livro Better Game Characters by Design: A Psychological Approach (2006), estudos indicam que muitas qualidades podem ser atribuídas a pessoas com características atraentes, como serem mais gentis, fortes, extrovertidas, persuasivas, dominantes e até mesmo mais inteligentes, sendo esse julgamento conhecido como efeito halo. Isbistir (2006) ainda afirma que a maioria dos personagens de videogames são atraentes, se beneficiando do efeito halo, que incentiva os jogadores a vê-los mais inteligentes, mais fortes, mais gentis e mais socialmente habilidosos.

Ao decorrer do tempo outras personagens femininas diferenciadas foram lançadas, como a Poppy, a segunda yordle fêmea lançada em 2010. Em sua splash art original, Poppy apresentava uma armadura angular com cota de malha que protegia o seu corpo inteiro, além de um martelo e um escudo de aparências bem pesados. Sua pele azulada e sua expressão brava poderiam indicar facilmente que a personagem se tratava de mais um campeão masculino, se não fosse a presença de cabelos presos em forma de maria-chiquinha.

Em 2011 houve a possibilidade de mais uma inovação na representação da feminilidade com a personagem Orianna, uma máquina que costumava ser uma garota que adoeceu e teve que substituir seus órgãos por próteses elaboradas. Entretanto, em termos de inovação visual a personagem falhou, ao representar garota que virou máquina exatamente como uma garota metalizada. Em sua splash art original seu corpo possui a forma de uma mulher, com direito a seios de metal que lembram boob plate e adereços mecânicos em formato de saia.

Sejuani foi lançada em 2012 e é a líder da nação Freljord, sendo esta uma terra severa e implacável. Orgulhoso e ferozmente independente, seu povo é composto de guerreiros natos, com uma forte cultura de saqueamento ${ }^{12}$. Segundo a biografia de Sejuani, ela foi educada em barbaridade e rispidez. Freljord é um lugar com inverno interminável e extremo, que moldou a campeã para ser implacável e resistente ${ }^{13}$. Apesar de toda essa descrição sobre o inverno extremo e terra severa, a campeã é representada em sua splash art original como uma mulher seminua, vestindo uma armadura em forma de biquíni, expondo sua cintura fina e destacando seus seios em plena tundra glacial montada em seu javali Bristle. A personagem possuía uma aparência inverossímil para uma guerreira que vivia em um ambiente gelado.

\footnotetext{
${ }^{12}$ Informações disponíveis em < https://universe.leagueoflegends.com/pt_BR/region/freljord/>. Acesso em 4 de dezembro de 2017.

${ }^{13}$ Informações disponíveis em < https://universe.leagueoflegends.com/pt_BR/champion/sejuani/>. Acesso em 4 de dezembro de 2017.
} 
Ainda em 2012 a última yordle fêmea foi lançada. Nomeada Lulu, a yordle é uma fada feiticeira, sendo a yordle que mais se assemelha a uma humana. Em sua splash art Lulu possui cabelos lisos e esvoaçantes, suas orelhas quase não são visíveis, parecendo uma simples menina com a pele roxa. Rodrigues (2014, p. 138) faz uma observação sobre as personagens femininas da raça yordle, dizendo que "por (elas) não serem fêmeas humanas, estas personagens não são sexualizadas e objetificadas".

Um grande impacto nas representações femininas diversificadas ocorreu em 2013, com o lançamento das personagens Quinn e Jinx. Quinn é uma patrulheira de elite, seu corpo é todo coberto por uma armadura, ela usa uma elmo que permite ver seu rosto e sua feição é de determinação. Ao contrário da maioria das personagens, os cabelos de Quinn não são muito visíveis, sendo bem escondidos pelo elmo. Ela utiliza uma leve armadura, com seios em formato de boob plate. As escolhas visuais de Quinn são explicadas pelo seu criador Michael Marino no trabalho de Rodrigues:

Quinn costumava ser um cara, então eu o transformei em uma mulher. Essa mulher é uma patrulheira, ela está preparada para uma luta, ela está vestindo uma armadura mais grossa, mas não metal, exceto em pontos-chave onde ela teria que interagir com o inimigo. Quinn não foi projetada para ter uma roupa colante. Tentou-se fazer isso e se parecia, mais uma vez, como uma mulher de capa com uma roupa apertada na pele, o que já tinha sido trabalho até a morte em Zyra, Syndra, Elise, e Diana. Ela não se preocupa em parecer feminina, ela se preocupa com utilidade. Uniforme largos com bolsos, joelheiras para cavar o chão para apoiar e mirar um tiro, nenhuma carne exposta para tomar uma arranhão. [...] Em relação a feminilidade, me chamaram a atenção há muito tempo, quando Sejuani [outra personagem feminina sexualizada] foi lançada com o raciocínio de que Sejuani pode usar menos roupas para que "você possa dizer que ela é do sexo feminino." Isso é um argumento inválido e uma triste desculpa para projetar de uma maneira particular. Um guarda florestal, uma elite, não se importa se você pode dizer que eles são uma mulher ou um homem. Eles estão interessados em ter seu trabalho feito, e ter o equipamento para fazer isso (MAURINO, apud RODRIGUES, 2014, p. 139).

Jinx foi a segunda personagem lançada em 2013 que causou alvoroço na comunidade de League of Legends. Em sua análise sobre Jinx, Rodrigues afirma que:

Jinx é então a primeira personagem feminina considerada "adulta" a não apresentar seios fartos. Muito pelo contrário, mesmo trajando apenas um biquíni, Jinx não tem seus seios destacados, seu peito sendo praticamente "plano". Em termos gerais o visual da personagem com tatuagens coloridas, coturnos e shorts rasgados a aproxima de um visual "punk" e sua costumeira associação à "marginalização social", alguém "desviante da norma". Jinx apresenta unhas pintadas de preto, roupas com detalhes rosas e uma série de acessórios como cintos de balas e cintos de couro, além de suas duas gigantescas armas de tiro, que dão-lhe um ar agressivo. Em contraste com isso, seu rosto delicado e longos cabelos presos em duas tranças aproximam-na de marcadores de feminilidade e também de infantilidade. Entretanto um pouco disto é desviado pela expressão "delirante" e "insana" da personagem, com seus olhos arregalados num tom vibrante de rosa-avermelhado e sorriso malicioso. Suas tranças ao vento proporcionam movimento (RODRIGUES, 2014, p.143).

Rodrigues (2014) ainda afirma que apesar dos cabelos de Jinx serem longos, eles não possuem a função de acentuar a feminilidade da personagem, e sim, torná-la excêntrica, utilizando a cor azul. 
mais angulosas, retilíneas. A pose da personagem é estável e não contorcida e ao mesmo tempo em que as pernas abertas sexualizam o visual da personagem (acentuado pelo ângulo de leve contra-plongé) esta posição é também uma espécie de contravenção de feminilidade tradicional, onde as normas culturais ditam que "uma mulher não deve escancarar suas pernas". A pose de Jinx está muito próxima de uma "pose masculina", com o pé displicente apoiado sobre uma rocha (RODRIGUES, 2014, p.144).

Bourdieu (2003) afirma que existem princípios antagônicos na identidade masculina e na identidade feminina, onde existe uma naturalização na identidade feminina que a força a se servir do corpo, ou de manter a postura, onde a submissão feminina encontra sua tradução natural no fato de se inclinar, abaixar-se, curvar-se, nas posturas curvas, na docilidade, etc., onde a mulher recebe uma educação de como postar todo o corpo, a maneira de andar, de erguer a cabeça ou os olhos, etc. A personagem Jinx aventura-se ao utilizar uma "pose masculina", indo contra a convenção de como uma mulher deveria se portar.

Às vezes alguns personagens passam por atualizações, sejam na biografia, na jogabilidade, modelo 3D ou splash art. Essas atualizações servem para melhorar a experiência do jogador com o jogo, para atualizar a estética do jogo e tornar alguns personagens mais críveis em relação a temática do universo de League of Legends. Em 2013, Sejuani recebeu uma atualização visual em seu modelo 3D e splash art, recebendo uma armadura de ferro pesada, com peles e forros para suportar o frio, transmitindo vigorosamente a ideia central do conceito da personagem. Apesar da atualização visual, sua armadura continuou com a presença de boob plate, reforçando o gênero da personagem.O modelo visual antigo permaneceu no jogo, como a $\operatorname{skin}^{14}$ "Sejuani Tradicional".

O ano de 2014 trouxe Kalista para a coleção de campeãs diversificadas. Kalista é um espírito imortal da vingança, invocado para caçar desertores e traidores. Antes de morrer, Kalista foi uma general leal e honrada, que foi morta em uma traição ${ }^{15}$. Kalista possui um visual sombrio, sua pele é azulada, semelhante a um morto-vivo, ela possui garras e veste uma armadura com boob plate. Entretanto, Kalista não é erotizada. Seus seios são pequenos e seu corpo magro está contorcido de maneira ameaçadora. Apesar de possuir a pele dos braços e coxas exposta, a coloração e sombra de sua pele reforça a imagem de um ser sobrenatural, não sendo erotizada.

Logo em seguida, ainda em 2014, a segunda campeã feminina em forma de criatura foi lançada, sendo ela chamada de Rek'Sai. Em sua splash art, não existe nenhum marcador de feminilidade. Apenas é possível saber que Rek'Sai é uma campeã feminina através de sua biografia, até mesmo a dublagem da personagem omite essa informação, pois a campeã não possui uma voz feminina, ela não fala com palavras, ela se comunica apenas com grunhidos, rosnados e rugidos. A campeã apresenta um grande marco na representação diversificada do corpo feminino justamente por não possuir um corpo concebido tradicionalmente na forma feminina, e sim, ser uma criatura agressiva e ameaçadora, possuindo garras e dentes ameaçadores. Rek'Sai é um grande passo para a formulação de mais personagens femininas sem marcações binárias de gênero, que conforme Rodrigues (2014), em comparação com a variedade de personagens não-humanos masculinos, a falta de diversidade de personagens fica evidente.

Ainda em 2014, a jovem robótica Orianna recebeu uma atualização em sua splash art.

\footnotetext{
${ }^{14}$ Skin é o termo utilizado para se referir a visuais alternativos para os personagens.

${ }^{15}$ Informações disponíveis em < https://universe.leagueoflegends.com/pt_BR/story/champion/kalista/>. Acesso em 4 de dezembro de 2017.
} 
Possuindo uma pose mais dinâmica, Orianna se contorceu de forma a esconder seus seios metalizados, ganhando marcadores identitários femininos como traços finos e suaves do rosto, o corpo magro e curvilíneo. Ela parece estar dançando e a ênfase da imagem é em seu corpo robótico, porém, gracioso.

Ao final do ano de 2014 houve um pequeno aumento na taxa de representação das personagens femininas em League of Legends, passando de $27,5 \%$ para $34,2 \%$.

Em 2015 tivemos o lançamento dos Kindred, dois personagens distintos que jogam como um único personagem dentro do jogo. Os Kindred são representados pela forma do Lobo e pela forma da Ovelha, sendo o Lobo masculino e a Ovelha feminino. Pode-se dizer que a forma feminina, a Ovelha é a forma dominante, já que ela pode ser controlada durante o jogo, sendo o Lobo ativado apenas em habilidades disponíveis para o jogador durante o jogo. A Ovelha, apesar de ser um ser antropomórfico, não possui marcadores de feminilidade, que só é identificada através de sua biografia ${ }^{16}$ e dublagem.

Illaoi foi lançada logo em seguida, sendo a primeira campeã feminina da classe Colosso ${ }^{17}$. Segundo a biografia da personagem, todos que a encontram ficam estarrecidos com a sua presença $^{18}$. Illaoi se diferencia de todas as campeãs por possuir um físico poderoso, seu corpo é forte e definido. Em sua splash art é possível vê-la em uma posição empoderada, captada por um contra-plongée $^{19}$. A pose de Illaoi é uma espécie de violação à feminilidade tradicional, onde segundo Bourdieu (2003) as posturas estão carregadas de uma significação moral, como se a feminilidade se medisse pela arte de "se fazer pequena", limitando o território deixado aos movimentos e aos deslocamentos de seu corpo. Illaoi vai em direção oposta a essa norma, sendo ela expansiva, grande e dominadora. Em sua splash art Illaoi possui a pele dos braços exposta, entretanto seus braços são marcados por tatuagens e músculos. Suas mãos são grandes e brutas. Seus braços estão abertos, assim como suas pernas, conquistando o seu espaço. Os marcadores identitários femininos encontrados em Illaoi são: cabelos longos esvoaçantes, seios e uma leve maquiagem sombria, entretanto nenhum deles serve como forma de erotizar a personagem.

Pode-se mencionar, por exemplo, o relato do designer criador de Illaoi, conhecido como "Fizznchips", obtido no site oficial de League of Legends:

Antes de iniciarmos o visual da nova moça lutadora, sabíamos que queríamos algo diferente. Este não é um fato muito conhecido, mas grande parte das Campeãs de League têm um rosto e corpo idêntico (ou quase idêntico) e são apenas diferenciadas por seu cabelo e roupas. Queríamos tentar algo diferente, então começamos a criar alguém significantemente diferente do resto para a nossa lutadora. Ela é maior, obviamente - mas além de seu formato grande, demos a ela uma grande personalidade. Queríamos que ela se sentisse confiante e confortável em sua própria pele, uma mulher que sabe exatamente quem é e o que quer. Começamos a trabalhar nela para que ela fosse alguém

\footnotetext{
${ }^{16}$ Informações disponíveis em < https://universe.leagueoflegends.com/pt_BR/story/champion/kindred/>. Acesso em 4 de dezembro de 2017.

${ }^{17}$ Colosso é uma classe de campeões dentro de League of Legends, classificando campeões resistentes, poderosos, com força bruta e que utilizam ataques corpo-a-corpo.

${ }^{18}$ Informações disponíveis em < https://universe.leagueoflegends.com/pt_BR/champion/illaoi/>. Acesso em 4 de dezembro de 2017.

${ }^{19}$ Contra-plongée ou câmera baixa, é o enquadramento de câmera que está abaixo do nível dos olhos, voltada para cima, podendo sugerir superioridade.
} 
genuinamente linda de uma maneira única. ${ }^{20}$

No primeiro semestre de 2015, Tristana recebeu uma atualização visual em seu modelo 3D e em sua splash art, tornando-se mais magra e com orelhas mais pontudas. Seu visual ficou mais ágil, Tristana é uma atiradora saltitante, então o antigo modelo com armaduras não era crível. Em sua nova splash art, Tristana passa a essência da personagem, seu corpo magro indica a agilidade que a personagem precisa ter para pular e seu corpo mantém o padrão de não erotizar as personagens da raça yordle, porém, tornando-as mais meigas.

Já no segundo semestre de 2015, foi a vez de Poppy ter o seu visual remodelado, passando de uma baixinha carrancuda para uma pequena e graciosa yordle. Sua cabeça ficou em formato mais simétrico, suas feições mais suaves, seus cabelos mais bonitos e esvoaçantes, sua pele já não tão azulada, ficando entre tons de azul e violeta, combinando com seus olhos em tons de violeta. Sua armadura ficou menos pesada, mas ainda assim forte, blindada e sem boob plate. Sua imagem ficou condizente com o universo fofo que a raça yordle procura representar.

A primeira personagem humana com características andróginas foi lançada em 2016. Ela é Taliyah, uma maga nômade, uma adolescente que controla pedras. Taliyah possui sobrancelhas grossas, cabelos curtos bagunçados, nariz proeminente e uma aparência andrógina. A falta de marcadores visuais femininos como seios fartos e maquiagem, permite que o jogador questione 0 gênero de Taliyah. Em seu lançamento, Taliyah teve sua aparência muito criticada, a personagem foi descrita pelos jogadores como "feia" e "nada sexy" ${ }^{21}$. Segundo o relato do designer criador de Taliyah, Daniel "ZenonTheStoic" Klein, obtido no site ESPN:

Taliyah é uma jovem lutando com um poder elemental diferente de qualquer coisa já vista. Ela é uma garota lutando para proteger seus entes queridos de um antigo poder e preocupada de que vá feri-los. Ela é uma garota crescendo em uma época de conflitos centrada em sua terra natal, e sua viagem é um dos domínio sobre seu poder. Quando, no meio disso tudo, ela iria falar: 'e enquanto isso eu vou ser sexy para o meu encontro em Shurima?'. 22

No primeiro semestre de 2017, Sejuani recebeu uma atualização na splash art da sua skin tradicional, despindo Sejuani de seu elmo, revelando uma campeã atraente com cabelos claros, olhos azuis e corpo curvilíneo, evidenciado pela pele exposta das coxas e costas.

Em 2017, a personagem erotizada Evelynn passou por uma reformulação visual e uma nova origem em sua biografia:

Nas fronteiras sombrias de Runeterra, a criatura demoníaca Evelynn busca sua próxima vítima. Ela atrai sua presa com a voluptuosa fachada de uma fêmea humana, mas basta alguém sucumbir aos seus encantos para que sua verdadeira forma seja revelada. Evelynn então sujeita a sua vítima a um tormento indescritível, comprazendo-se com a dor alheia. Para a criatura, esses contatos são apenas casinhos inocentes; para o resto de Runeterra, são contos macabros de luxúria trágica e terríveis lembretes sobre o custo da volúpia

\footnotetext{
${ }^{20}$ Informações disponíveis em: <https://br.leagueoflegends.com/pt/news/champions-skins/championpreview/analise-de-campeao-illaoi>. Acesso em 5 de dezembro de 2017.

${ }^{21}$ Informações disponíveis em < http://espn.uol.com.br/noticia/597021_league-of-legends-jogadores-reclamamsobre-taliyah-ser-feia-e-nada-sexy-designer-responde>. Acesso em 5 de dezembro de 2017.

${ }^{22}$ Informações disponíveis em .< http://espn.uol.com.br/noticia/597021_league-of-legends-jogadores-reclamamsobre-taliyah-ser-feia-e-nada-sexy-designer-responde>. Acesso em 6 de dezembro de 2017.
} 
descontrolada. $^{23}$

Após a reformulação da biografia da personagem, baseando-se na criatura mitológica Súcubo $^{24}$, o corpo curvilíneo e atraente de Evelynn tornou-se verossímil, não sendo atraente apenas para agradar os olhos dos jogadores, mas sendo atraente para usufruir da mitologia da personagem. Evelynn se aproveitou do estereótipo da femme fatale para criar a imagem ideal que a personagem precisa transmitir: uma fêmea assassina. $O$ uso de estereótipos na construção de personagens pode trazer consequências positivas:

\begin{abstract}
Apesar de suas desvantagens, os estereótipos servem para um propósito importante - eles ajudam as pessoas a fazer avaliações rápidas para que não tenham que avaliar cada pessoa completamente "a partir do zero". O processo inconsciente de comparar o que é visto com os protótipos já na mente e depois usando combinações para fazer suposições sobre essa pessoa, economiza tempo e esforço. Isso é importante, dada a curta janela de tempo normalmente disponível ao conhecer alguém novo. Os estereótipos também ajudam a tornar os encontros sociais diários mais previsíveis, se nós e outros adotarmos um determinado código de estereótipo em nossa vestimenta e comportamento, podemos ter muita confiança em que seremos "lidos" como planejamos (ISBISTER, 2006, p. 13) 25.
\end{abstract}

Em 2017, a campeã Xayah foi lançada. Apesar de não ter inovação visual ou representação diferenciada do corpo feminino e possuir muitos marcadores femininos, como cabelos esvoaçantes, maquiagem, adereços como piercing, corpo curvilíneo e pele exposta, Xayah inovou seu lançamento em League of Legends ao ser lançada em dupla com outro personagem que compõe a mesma narrativa, seu parceiro e amante Rakan. Em um lançamento inédito, ambos os personagens compartilham suas splash arts, assim como as splash arts de suas skins. A inovação ocorre nas hierarquias de gênero, já que Xayah é a atiradora ${ }^{26}$, uma atacante à distância, a ativa, e Rakan é o suporte ${ }^{27}$, um campeão que ajuda seus aliados, o passivo. Xayah não é a primeira atiradora feminina, entretanto, é a primeira vez que League of Legends lança dois personagens em conjunto, tendo a personagem feminina como atiradora.

Simbolicamente voltadas à resignação e à discrição, as mulheres só podem exercer algum poder voltando contra o forte sua própria força, aceitando se apagar, ou, pelo menos, negar um poder que elas só podem exercer por procuração (BOURDIEU, 2003, p. 43).

Neste relacionamento, Xayah não apenas exerce o poder dominante, como quebra a resignação e discrição, sendo ela uma revolucionária que ataca quem quer que fique em seu caminho ${ }^{28}$.

\footnotetext{
${ }^{23}$ Informações disponíveis em: < https://universe.leagueoflegends.com/pt_BR/champion/sejuani/>. Acesso em 4 de dezembro de 2017.

${ }^{24}$ Súcubo é uma personagem mitológica, um demônio com aparência feminina.

${ }^{25}$ Tradução livre minha. No original: Despite their drawbacks, stereotypes do serve an important purpose - they help people make quick assessments so that they do not have to evaluate each person completely "from scratch." The unconscious process of comparing what is seen with prototypes already in the mind and then using matches to make assumptions about that person, saves time and effort. This is important, given the short window of time normally available when meeting someone new. Stereotypes also help make everyday social encounters more comfortably predictable, If we and others adopt a given stereotype code in our dress and behavior, we can be pretty confident that we will be "read" the way we have planned.

${ }^{26}$ Atirador é uma classe de campeões com alto poder de ataque à distância.

${ }^{27}$ Suporte é uma classe de campeões de alta utilidade para auxiliar seus aliados.

${ }^{28}$ Informações disponíveis em < https://universe.leagueoflegends.com/pt_BR/story/champion/xayah/>. Acesso em 5
} 
Zoe foi a última campeã lançada. Apesar de sua aparência infantil, Zoe é um ser ancestral. Zoe possui a forma de uma criança, seu corpo é magro, sem seios, suas roupas são coloridas, seus lábios são bem finos e seus olhos bem grandes, remetendo a personagens da Disney. Seus cabelos são extremamente longos e esvoaçantes, um tanto quanto rebeldes. Zoe passa uma imagem muito infantil com tantas cores e sua face feliz, evocando uma personalidade brincalhona e calorosa:

O viés humano é assumir que aqueles que têm cara de bebê são mais quentes e mais confiáveis, mas também podem ser mais dependentes, menos responsáveis e mais submissos e manipuláveis. Os psicólogos chamam isso de uma generalização exagerada: atribuir traços de uma criança a adultos com características infantis (ISBISTER, 2006, p. $10)^{29}$.

Tendo em vista aspectos observados por Isbister (2006), Zoe não foi formulada para impor a imagem de dominadora, ao contrário de Illaoi, Zoe transmite a imagem que condiz com a sua aparência e biografia, uma jovem que apenas quer se divertir e fazer travessuras.

Em comparação com o trabalho de Rodrigues (2014), observa-se algumas mudanças. Rodrigues constata que $92 \%$ das personagens possuiam corpos curvilíneos e magros, $57 \%$ possuiam seios fartos, sendo este o marcador de feminilidade mais comum no jogo, $22 \%$ das personagens utilizavam salto alto, apesar de serem guerreiras e $47 \%$ aparentavam utilizar alguma maquiagem. Com a atualização do elenco de personagens, 8 novas personagens femininas foram lançadas e constata-se que $70,2 \%$ das personagens femininas possuem corpos curvilíneos e magros, os seios continuam sendo destaques em $53,3 \%$ das splash arts e 59,6\% das personagens aparentam utilizar algum tipo de maquiagem. Na análise realizada nas splash arts, apenas 6,4\% das personagens utilizam salto alto, $46,8 \%$ não utilizam salto alto e $46,8 \%$ não possuem os pés visíveis para análise. $\mathrm{Na}$ análise realizada nos modelos 3D das personagens, observa-se que $23,4 \%$ possuem salto alto, sendo este dado próximo ao de Rodrigues. A criação de personagens diversificadas refletiu diretamente nos tipos de corpos criados dentro do jogo, passando a oferecer personagens com corpos diversificados, como corpos fortes, corpos apenas magros, corpos antropomórficos ou em formas de criaturas não humanas, e outros. Essa evolução fica clara ao comparar os dados com o trabalho de Rodrigues.

\footnotetext{
de dezembro de 2017.

${ }^{29}$ Tradução livre minha. No original: The human bias is to assume that those who have babyfaces will be warmer and more trustworthy but also may be more dependent, less responsible, and more submissive and manipulable. Psychologists call this an overgeneralization: attributing traits of a child to adults with childlike features. The babyface bias has been shown to affect judgments of people from infancy to old age. The babyface effect transcends cultural and even species lines - people find baby animals just as cute and nurturable as baby humans.
} 
Quadro 1. Infográfico sobre os corpos femininos em League of Legends.

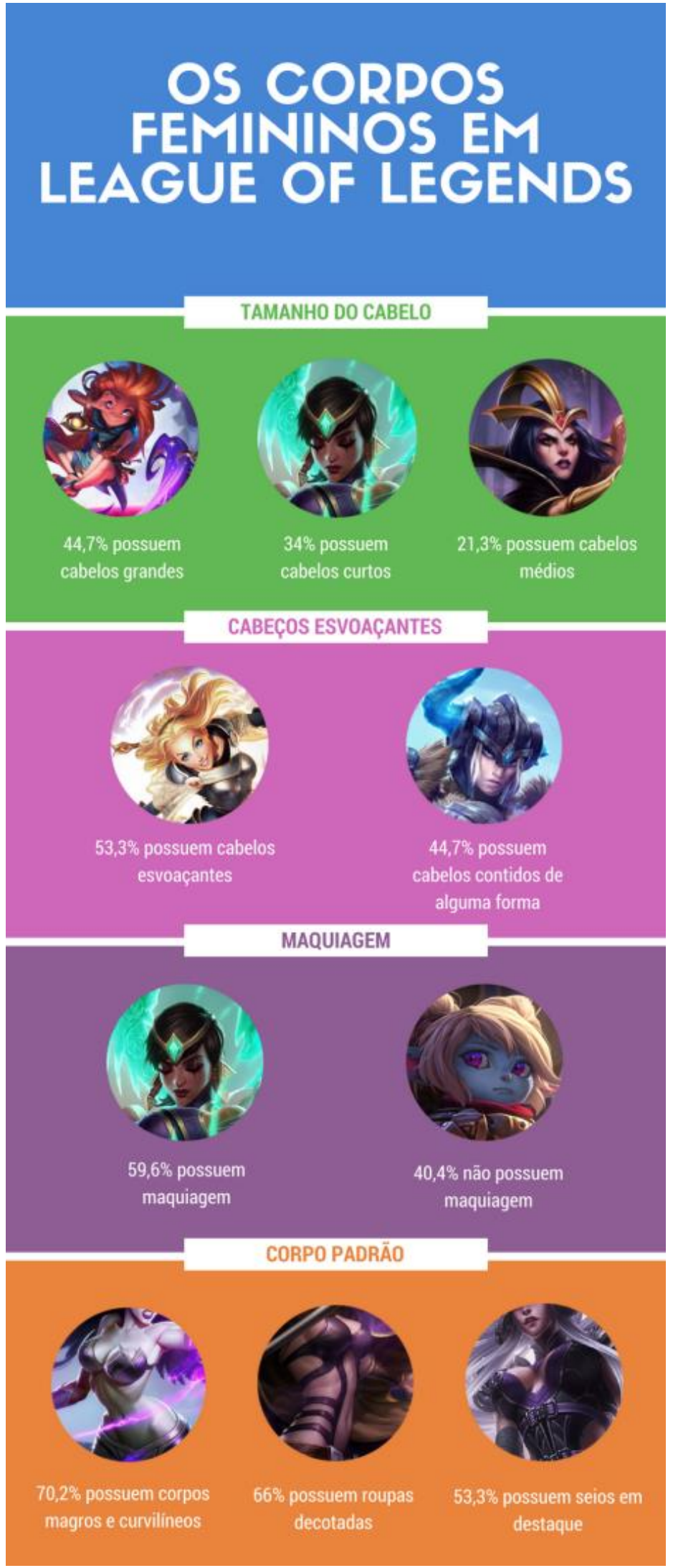

Fonte: Victor Henrique Nunes 


\section{Considerações Finais}

Em virtude dos dados apresentados, entende-se que apesar de muitas personagens serem concebidas de maneira idealizada, existem maneiras de reformulá-las e torná-las críveis, como a atualização visual dos modelos em 3D e splash arts ou a atualização da biografia. Percebe-se que essas mudanças tornam-se necessárias dentro do universo de League of Legends, quando as personagens são apresentadas de maneira que não possam ser justificadas dentro daquele universo, visto que personagens como Sejuani e Evelynn passaram por grandes grandes atualizações, visuais e biográficas, para comporem o universo do jogo de maneira verossímil.

Apesar das atualizações visuais ajudarem a mudar histórias, corpos e personagens, elas não são indicativos de que as personagens deixarão de serem idealizadas, como por exemplo a campeã Sejuani que teve seu modelo 3D remodelado para se encaixar em sua temática, entretanto continuou usando uma armadura com boob plate, para reforçar a sexualidade da personagem. Essa é uma solução ultrapassada, pois existem outras maneiras de indicar que determinadas personagens são do gênero feminino, como por exemplo através da sua biografia e dublagem, não sendo necessário o uso de boob plates ou decotes reveladores.

Levando em consideração os aspectos observados neste estudo, nota-se um aumento na demanda de criação de personagens diversificadas. Esta demanda possivelmente parte dos próprios designers da Riot Games, como pode ser observado através dos relatos apresentados, onde a equipe criativa se empenha em criar novas personagens com características diferenciadas, deixando de lado personagens idealizadas e erotizadas. Entretanto, personagens erotizadas continuam sendo lançadas, uma vez que parte do público apresenta certa rejeição, com personagens diferenciadas, como Taliyah, a adolescente com características andróginas. Essa rejeição é possivelmente motivada pela preferência por personagens femininas idealizadas e sexualizadas, sendo esta preferência cultural.

Conforme os dados analisados do jogo durante os anos de 2009 a 2017, presume-se que a taxa de representatividade das personagens femininas no jogo continue por volta de $35 \%$ nos próximos anos, entretanto, mais personagens com corpos diversificados poderão ser lançadas no vasto universo que League of Legends oferece, aumentando o catálogo, visto que parte da equipe de criação do jogo dedica-se para oferecer maior diversidade de personagens.

\section{Referências}

Brandmore and Magnus. 2016 League of Legends World Championship By the Numbers. 2016. Disponível em <http://www.lolesports.com/en_US/articles/2016-league-legends-worldchampionship-numbers>. Acesso em: 22 de julho de 2017.

ADAMS, Ernest. Fundamentals of Game Design, Second Edition. Berkeley, CA: New Riders, 2009.

BERALDO, Beatriz . O que é feminilidade? Papéis sociais e o feminismo contemporâneo.

Comunicon, 2014, São Paulo. Anais Comunicon 2014. São Paulo: FAPESP/ESPM, 2014. v. 1. p. 1-15.

Disponível em: <

http://www.espm.br/download/Anais_Comunicon_2014/gts/gt_cinco/GT05_BERALDO.pdf>.

Acesso em 5 de dezembro de 2017. 
BOBANY, Arthur. Video Game Arte. Editora Novas Ideáis, Teresópolis, RJ, 2008.

BOURDIEU, Pierre. A Dominação Masculina. Trad. Maria Helena Kühner. Editora Bertrand Brasil, Rio de Janeiro, 2003.

GULARTE, Daniel. Jogos Eletrônicos 50 anos de interação e diversão. Editora Novas Idéias, 2010. HAMARI, Juho; SJÖBLOM, Max, What Is eSports and Why Do People Watch It? 2017. Internet research, 27(2). DOI: 10.1108/IntR-04-2016-0085, Forthcoming.

ISBISTER, Katherine (2006). Better Game Characters by Design: A Psychological

Approach. San Francisco: Morgan Kaufmann, 2006.

MENDES, Cláudio Lúcio. Jogos eletrônicos: diversão, poder e subjetivação. Campinas, SP: Papirus, 2006.

RODRIGUES, Letícia. Um estudo em representações gráficas nos jogos eletrônicos na perspectiva das relações de gênero: os tipos de feminilidades em League of Legends. Universidade Tecnológica Federal do Paraná, Curitiba, 2014. 